\title{
O funcionamento da subjetividade: um contraponto entre estudos comparatistas e a filosofia da linguagem russo-soviética
}

Ana Zandwais ${ }^{1}$

\begin{abstract}
This article aims to investigate questions of subjectivity that can explain the ways language functions in a concrete way. By comparing the notions of subjectivity presented in 'Essay of Semantics: science of meanings' of Michel Bréal published in 1897 and 'Marxism and the Philosophy of language' of Bakhtin \Voloshinov, published in 1929, we try, through our analysis, to show that these two conceptions of language, although differents, are very close.
\end{abstract}

Keywords: subjectivity, language, meanings, humanism, marxism

Resumo: Este artigo propõe-se a investigar questões de subjetividade que permitem explicar as formas através das quais a linguagem funciona de modo concreto. Estabelecendo relações de contraponto entre as noções de subjetividade presentes em 'Ensaio de Semântica: ciência das significações', de Michel Bréal, publicado em 1897, e 'Marxismo e Filosofia da Linguagem', de Bakhtin\Voloshinov, publicado em 1929, buscamos, através de nossas análises, mostrar que, não obstante diferentes, estas concepções de linguagem e de subjetividade estão muito próximas.

Palavras-chave: subjetividade, linguagem, significações, humanismo, marxismo

\section{Introdução}

Queremos iniciar este estudo pontuando uma questão que nos permite acessar determinadas bases de um discurso fundador nos domínios dos estudos de vertente marxista sobre a linguagem

Desde o momento de circulação de "Marxismo e Filosofia da Linguagem," durante os anos 1929, algumas questões que pareciam estar ao abrigo de importantes polêmicas, entre os lingüistas, filósofos da linguagem e filólogos, tais como a questão da subjetividade, que desconstrói a concepção de língua como objeto autônomo, a questão do signo, tomado como materialidade de todo ato simbólico e das relações entre sentido e história,

1 Docente dos Cursos de Graduação e Pós-Graduação em Letras da Universidade Federal do Rio Grande do Sul. 
a dialética entre a língua, tomada como objeto abstrato e suas condições empíricas de funcionamento, exploradas na obra de Bakhtin $\backslash$ Voloshinov (1986), passaram a tornar-se objetos de questionamentos sob a ótica de uma Filosofia da linguagem de base materialista.

Dentro deste quadro, faz-se necessário destacar que seus autores, já nas décadas de 1929-1930 realizavam com maestria inigualável reflexões acerca das tendências eurocêntricas de descrição das relações entre o objeto comum de estudo dos lingüistas e dos filólogos - a língua - e de suas intersecções ou não com questões de subjetividade e questões históricas e que viriam a caracterizar o contexto dos estudos comparatistas dominantes durante o final do século xix e o início do século xx.

Tomar “Marxismo e Filosofia da Linguagem' como uma referência para refletir em torno das relações entre linguagem, história e subjetividade, deste modo, torna-se fundamental,.já que, segundo nossa ótica, é nesta obra que são produzidas leituras críticas em torno das bases filológicas e linguísticas oriundas das formas de apropriação, por Bakhtin Voloshinov, de fontes eurocêntricas e que constituem um "vetor" de diferentes "tendências" entre: a) o que os lingüistas e os filólogos do "Leste" e do "Oeste" entendem por língua; b) as formas dominantes que caracterizam como os estudos comparatistas acerca da linguagem , realizados no final do séc. xix, na Europa, e no início do sec. xx são fundamentados: c) as condições através das quais pode-se pensar acerca de questões epistemológicas que aproximam os universos de pesquisas produzidas no Oeste e no Leste europeus.

Por outro lado, é preciso considerar que o final do sec. xix já apontava novos caminhos para os estudos da linguagem através da obra de Michel Bréal, que re-introduz os estudos semânticos no cenário francês e passa a tratar do elemento subjetivo como uma condição constitutiva do funcionamento da linguagem. Eis porque podemos pensar que a obra 'Ensaio de Semântica' pode ser tomada como um marco para o desenvolvimento dos estudos lingüísticos comparatistas no contexto do "Oeste".

Com base nas questões com as quais introduzimos este artigo, nosso escopo consiste em refletir em torno de concepções de linguagem, de subjetividade e de sentido produzidas em contextos históricos distintos. Uma produzida no contexto francês durante o final de século xix, mas que retoma as bases filosóficas dos estudos clássicos orientais, e outra produzida no início de sec. xx, no contexto soviético, e que não está alheia ao conhecimento dos estudos filológicos, lingüísticos e filosóficos dominantes no contexto europeu, embora não tivesse ainda se apropriado das diferenças marcantes, em relação a suas tendências contraditórias e que poderiam vir a caracterizar um novo quadro de referências teóricas e metodológicas.

A partir, pois, de um percurso que busca dar ênfase a diferentes modos de reflexão em torno das relações entre linguagem, sentido e história, caracterizando a condição de subjetividade do sujeito, trazemos para o centro de nossas reflexões um dos mais notáveis filólogos europeus do final do século xix, Michel Bréal, através de "Ensaio de Semântica: ciência das significações”(1897) e dois expoentes do contexto soviético: Volochinov, através de 'Chto Takoe Yazik (2011) e Bakhtin/Volochinov através de 'Marxismo e Filosofia da Linguagem, obra que passa a circular nos anos 1929.

Tentaremos, deste modo, estabelecer um contraponto entre as bases da filologia e dos estudos histórico-comparatistas ${ }^{2}$ e as bases de uma Filosofia da Linguagem de vertente

\footnotetext{
2 É importante salientar, desde já, que Michel Bréal dedicou-se tanto aos estudos clássicos, como aos estudos de Linguística histórica e veio a desenvolver suas reflexões de base semântica a partir de uma ótica historicistacomparatista, embora com questões próprias, distintas de outros contemporâneos como Hermann Paul,, que publica 'Princípios da História da Língua (1880) e Darmesteter que publica 'La Vie des Mots (1886) e ao qual ele faz referências em 'Ensaio de Semântica (1992:195).
} 
materialista presente nas obras de Volochinov e de Voloshinov/Bakhtin (1986), considerando, para tal fim, sobretudo, o fato de que a leitura de Bréal em torno de questões filológico-linguísticas seria distinta de outras leituras eurocêntricas dominantes à época, embora não totalmente conhecida dentro do contexto soviético nas três primeiras décadas do sec. $\mathrm{xx}^{3}$.

Perseguiremos, assim, tanto o objetivo de caracterizar sob que aspectos determinados pressupostos filosóficos, filológicos e linguísticos das obras de Michel Bréal e de Valentim Voloshinov, M. Bakhtin \V. Voloshinov poderiam aproximar-se, em torno de questões epistemológicas, bem como o objetivo de delimitar os aspectos de distanciamento entre as concepções de linguagem e de subjetividade exploradas por estes autores, tentando configurar, em última instância, como as contribuições destas obras, uma de tendências marcadamente historicista-comparatistas, outra de tendências marxistas; influenciam o cenário dos estudos lingüísticos e filológicos, questionando as bases epistemológicas positivistas dominantes tanto no cenário europeu como no cenário soviético durante o final do sec. xix e ao longo dos anos 1929-30.

\section{MICHEL BRÉAL: uma racionalidade humanista}

Se nos reportarmos às relações que Bréal (1992) estabelece entre linguagem e subjetividade, questão fundamental em sua obra, e que, segundo nosso ponto de vista, responde à ausência de enfoques humanistas nos estudos de base positivista ${ }^{4}$ desenvolvidos no século xix, é preciso enfatizar, em primeiro lugar, que para ele a linguagem somente pode ser compreendida em sua condição de estar simultaneamente atravessada pelos desejos, pela vontade, por sentimentos, por intervenções do sujeito em torno do que ele diz, ainda que tais intervenções não se coloquem de modo transparente ou totalmente consciente na linguagem.

É Bréal quem nos diz que, em relação às condições de uso da linguagem "somos ao mesmo tempo espectador interessado e autor dos acontecimentos" (id.,p.157), de tal modo que, para ele, todo ato de linguagem constitui-se em um ato de subjetividade, para o qual não há um álibi capaz de abstraí-lo de tal condição.

Entendemos ser importante dar destaque, a partir da observação das concepções apresentadas por Bréal em 'Ensaio de Semântica $(1992)^{5}$ ', que ele coloca em dúvida, ao contrário de outros pensadores de sua época, como Schleicher (1983) e Max Muller (1897), o postulado de que a Linguística seria uma ciência natural. A linguagem, para Bréal, não pode ser reduzida à mera condição de um organismo vivo, cuja vida, cujo trabalho seria independente dos trabalhos do intelecto e do desejo.

Assim, de acordo com sua posição, dentro das bases de segmentação da ciência em Ciências naturais e humanas e sociais, a Ciência da Linguagem deveria ser colocada no ramo

3 É importante salientar que iremos encontrar referências explícitas aos estudos desenvolvidos por Michel Bréal na obra de Antonio Gramsci 'Concepção Dialética de História'( 1989), que dá destaque às reflexões produzidas por Bréal acerca do funcionamento do trabalho metafórico na linguagem e cujos efeitos adquirem grande importância para as concepções de linguagem, tomadas em seu o aspecto orgânico dentro de uma teoria marxista.

4 Em um capítulo de ‘Ensaio de Semântica' intitulado ‘A Linguística é uma ciência natural? (1992:195)’Bréal tece duras críticas a Schleicher e à tese de Max Müller de que as línguas poderiam ser estudadas como 'fenômenos naturais, cujo desenvolvimento seria regido por 'leis próprias', de modo independente do trabalho humano. Para Bréal, o reducionismo de tais definições viria a colocar os estudos sobre a linguagem em terreno cômodo, mas, ao mesmo tempo, na inércia.

5 Para fins deste estudo, trabalhamos com a tradução para língua Portuguesa de 1992, lembrando, entretanto, que a obra original 'Essai de sémantique: science des significations' data de 1897. 
das ciências históricas, já que, para ele, a linguagem não possui consistência como objeto de investigação fora da observação do acúmulo histórico do trabalho lingüístico humano.

É, pois, a partir de uma concepção que busca caracterizar a Ciência da Linguagem como uma ciência humana e ao mesmo tempo histórica que Bréal irá debruçar-se sobre a especificidade do linguístico, sobre as condições de funcionamento da linguagem, em suas dimensões históricas e também lógicas, as quais não poderiam tomar simplesmente como paradigmas os pressupostos da lógica formal, já que estaria fora do escopo da lógica matemática intersectar questões de "objetividade e de subjetividade, bem como também estaria fora do escopo de uma ciência humanística descartar as relações entre linguagem e subjetividade.

Segundo Bréal (1992), deste modo, a lógica da linguagem, enquanto uma faculdade humana e resultado de trabalho histórico, não poderia ser enquadrada em parâmetros formalistas, na medida em que esta é capaz de suportar a concatenação de termos contraditórios em um mesmo enunciado, produzindo sentidos que não teriam qualquer aceitabilidade no âmbito de uma lógica por condições de verdade.

Assim, Bréal, ao dar destaque ao que se faz possível, no âmbito da lógica lingüística, remete para o fato de que o trabalho da contradição não seria um "deslize" no funcionamento da linguagem humana, mas, ao contrário, seria próprio desta busca caracterizar a especificidade da linguagem humana. Daí não haveria porque fazer coincidir as premissas da lógica formal com as do gênero discursivo, considerando que ambas se regeriam por leis distintas e que representariam realidades direcionadas para interesses opostos: uma voltada à abstração do sujeito na linguagem, outra, voltada para a intersecção entre razão, desejo e vontade, configurando a própria condição de multiplicidade do sujeito.

Cabe também observar que, para Bréal, a linguagem ordinária precisa ser analisada não somente como um dado, estático, mas, sobretudo, em termos de seus processos de transformação, porque aquilo que a transforma é o que a torna dinâmica, viva. Deste modo, seria tarefa essencial do investigador olhar para os fatos de linguagem e, ao mesmo tempo, para as suas transformações, sem estar simplesmente fundamentado em relações de base dedutiva, calcadas na observação estrita das mudanças, dos deslocamentos que podem ocorrer em suas estruturas internas, já que, segundo Bréal, 'a lógica popular', que pode ser entendida como o motor que move a língua, avança em etapas nem sempre visíveis para o filólogo ou para o lingüista.

Esta questão, segundo nossa ótica, merece destaque na obra de Bréal, pois permite não somente inscrever sua visão de linguagem dentro de uma esfera historicista, mas também em uma esfera humanista de ciência, já que de acordo com o pressuposto de que seria a lógica dos usuários da língua que a move, não somente torna-se inconseqüente fazer coincidir a lógica do lingüista ou do filólogo com a lógica da língua, mas também irreal, porquanto os sentidos se deslocam por razões diferentes daquelas apresentadas pelo lingüista e pelo filólogo. É, portanto, necessário estar atento à diversidade dessas duas lógicas. E Michel Bréal irá privilegiar a lógica dos falantes. E sobretudo pelo fato de que a lógica das massas parte de pontos circunscritos e intervém sobre a estabilidade da língua, a partir de 'diferentes marchas' que se caracterizam por serem fragmentadas em suas relações com a história.

Sob tal perspectiva, portanto, a língua pode ser analisada sob diferentes ângulos, os quais precisam, entretanto, recuperar, conforme a posição de Bréal,' a marcha do povo'. Sem esta 'marcha', para Bréal, não haveria história concreta, e nem condições reais para tratar do funcionamento da subjetividade na linguagem. 
Desde esta ótica, as relações analógicas que sustentam o funcionamento empírico e as transformações de uma língua, as quais serão investigadas por Bréal (id.,p.155), a partir de uma perspectiva historicista-comparatista ${ }^{6}$, não podem ser abstraídas, senão com base em um princípio fundamental: o princípio:de que a linguagem, sendo obra de seus falantes, obra do povo, e não dos lógicos e filólogos, precisa ser estudada através de olhares capazes de percorrer os mesmos caminhos que os falantes, que as massas percorrem. E nisto residiria uma das grandes dificuldades dos estudos sobre a linguagem do final do sec. xix, segundo ele, já que os estudos comparatistas dominantes deste período estão voltados notadamente para a descrição das relações de equidade entre as línguas, ou para a descrição dos modos de transformação de suas estruturas.

$\mathrm{Na}$ medida, pois, em que os lingüistas atribuem ao funcionamento da língua uma vida própria, que independe da vontade, do desejo humano, são as regularidades que marcam sua fixidez, mas que também apagam sua natureza de permanente transformação, apagando, assim, a própria história que a constitui , tornando-a, segundo Bréal, uma espécie de "quarto reino" (id.,p.195). Reino intocável, intangível para seus falantes.

Entretanto, para o autor, esta dimensão que se pauta pelo excesso de abstrações construídas em torno da língua(gem) não seria privilégio somente dos cérebros positivistas, mas também teria sofrido influências dos estudos bíblicos.

Bréal faz referência ao dicionário de língua alemã dos irmãos Grimm (id.,p.196) que traz em sua primeira página a seguinte epígrafe: "No princípio era o verbo", observando o importante papel que tal epígrafe cumpre neste dicionário, na medida em que é através dela que se dá o reconhecimento mútuo entre autor e leitor. Trata-se de supor a existência de uma língua idealizada, transparente, não ambígua e dotada de absoluta fluidez: a língua da gênesis, “um arquétipo superior' que permite inferir que o 'verbo' seria já fluido desde o princípio, e que também contribui para apagar as histórias de criação e de produtividade lingüística dos povos, de suas diferentes formas de simbolização, de estratificação, fortalecendo, deste modo, a crença na existência de uma "língua-mãe" soberana entre as demais: não híbrida, sem falhas, que não necessita de estágios para vir a ser: uma 'língua messiânica', e, que, em virtude do êxito do imaginário que produz entre aqueles que se identificam com o 'axioma' de que ‘ no princípio era o verbo' pode ser associada à língua-mãe de uma família hegemônica de línguas: a indo-européia.

Deste modo, quer pelo viés de uma teoria naturalista, que toma a Ciência da Linguagem como uma ciência natural, onde a vida das línguas não depende do trabalho racional e histórico dos homens, quer pelo viés de pressupostos de teorias místicas, conforme Bréal (id.,p.197), os estudos em torno da linguagem acabam por abstrair dela aquilo que ela teria de mais característico: sua condição de constituir-se, sob diferentes formas de ordenamento simbólico, a partir das relações inevitáveis de inscrição do sujeito em seu funcionamento e, ao mesmo tempo, de transformar os sujeitos no próprio processo de apropriaçãolintervenção destes sobre seus objetos simbólicos ao longo de diferentes histórias.

Por fim, para Bréal, é em virtude do papel que a história cumpre que se pode pensar que se as leis da linguagem são necessárias, elas são ao mesmo tempo cegas, na medida em que não se sustentam por si mesmas, mas necessitam dos acontecimentos para que justifiquem a sua própria condição de necessidade. E estas seriam algumas das razões

$6 \mathrm{O}$ autor reflete em torno do funcionamento do princípio da analogia como uma necessidade de reprodução, ao longo do tempo, entre as formas, a partir de associações, com vistas a dotar a língua de regularidades. Ao refletir sobre o modo como as massas constroem relações analógicas, Bréal coloca em perspectiva diferentes lógicas que regulam seu funcionamento. 


\section{Conexão Letras}

fundamentais, através das quais poder-se-ia fundamentar os fatos de que nem a Ciência da Linguagem seria uma ciência natural, nem a linguagem teria vida própria fora de uma realidade histórica.

\section{BAKHTINIVOLOCHINOV: uma tendência filosófico-marxista}

Em "Marxismo e Filosofia da Linguagem (1986)7, vamos encontrar preocupações semelhantes àquelas postuladas por Michel Bréal, na perspectiva de sustentar que a Linguística não seria uma ciência inscrita no ramo das ciências naturais, não obstante as motivações dos autores em propor questões que estariam comprometidas com leituras materialistas, mas não-mecanicistas sobre a linguagem, permitam-nos delimitar um conjunto de pressupostos também não tangenciado pelos estudos eurocêntricos sobre a linguagem, desenvolvidos nos anos 1920-30, ${ }^{8}$. Façamos, então, uma leitura das questões envolvidas nas relações entre linguagem, subjetividade e história desde uma ótica da Filosofia da Linguagem de vertente materialista.

Ao perguntarem-se em que consiste o objeto da Filosofia da linguagem, qual a sua natureza concreta, com que metodologia estudá-la, na mesma medida em que admitem a inexistência de estudos de Filosofia da linguagem de vertente marxista no contexto soviético ${ }^{9}$, os autores remetem às bases filosóficas de estudos desenvolvidos pelo filósofo alemão Ernst Cassirer (2001) sobre as formas simbólicas. São questões postuladas por Cassirer que os autores tomam como paradigmas para desenvolver determinadas reflexões em torno do signo, o que demonstra, que os estudos de vertente marxista, sobretudo em torno da lógica simbólica, já teriam passado por outros estágios de maturação sofrendo influências de correntes européias ${ }^{10}$..

As relações entre linguagem e subjetividade, contudo, irão adquirir uma feição própria em "Marxismo e Filosofia da Linguagem", na medida em que a linguagem, como objeto empírico, somente pode ser estudada no seio de uma sociedade organizada (id.,p70) e nas situações concretas em que ela se produz, a fim de que se torne objeto de investigações, onde o social e o individual se interpenetram e se fundem, enquanto parte de um fenômeno que deve ser ao mesmo tempo social e ideológico..

Como vemos, é a concepção de linguagem proposta por Bakhtin $\backslash$ Voloshinov (1986) que lhes permite delinear um conceito de subjetividade, conforme demarcaremos a seguir. Ao estabelecerem relações de fusão entre o social e o individual, os autores necessitam rever o que entendem por ordem da "individualidade" E o fazem considerando que "o indivíduo enquanto detentor de conteúdos de sua consciência, enquanto autor de seus pensamentos, enquanto personalidade responsável por seus pensamentos e desejos" somente pode ser

\footnotetext{
7 Para fins de realização deste estudo estamos trabalhando com versão em língua Portuguesa de Marxismo e Filosofia da Linguagem' (1986), embora estejamos consultando, simultaneamente, aversão em língua Inglesa(1986) e a versão mais recente em língua Francesa (2009).

8 Cabe observar que, ainda que Marx ( 2007) tenha refletido em torno da ideologia, redefinindo a concepção hegeliana de ideologia, no sentido de torná-la materialista, não desenvolveu uma reflexão específica capaz de articular as relações entre linguagem e ideologia.

9 É importante salientar a observação feita no capítulo 4, intitulado “ Das Orientações do Pensamento Filosóficolinguístico" (ibid.,p 71), através de uma nota de rodapé, em que os autores afirmam:” o único esboço atual relativamente sério de história da filosofia da linguagem e da lingüística acha-se no livro de Ernst Cassirer, A Filosofia das Formas Simbólicas."

10 Cabe lembrar que paralelamente ao domínio da língua Russa, os intelectuais soviéticos teriam domínio da língua Alemã, já que para penetrar nos campos da ciência e, sobretudo, da Filosofia seria preciso também dominar questões da cultura e da língua alemã.
} 
entendido como um efeito de fenômenos sócio-ideológicos (id,p.58). Assim, o conteúdo do psiquismo "individual" é social e ideológico, ao mesmo tempo, e precisa estar calcado em uma ordem simbólica, cuja materialidade é sígnica, por um lado, e histórica por outro.

A partir desta ótica, o processo de tomada de consciência, pelo sujeito, de sua individualidade, segundo Bakhtin \Voloshinov, não é nem totalmente interno, nem totalmente externo, mas está condicionado às determinações históricas e ideológicas, de tal modo que o conceito de "individualidade" como tal só poderia ser inscrito dentro do campo biológico, ao contrário da noção de indivíduo, cuja "personalidade" não tem existência fora do campo social.

A partir desta lógica, entretanto, a própria noção de "individualidade" seria um mito, na medida em que ela está sempre sendo afetada por algo que lhe é exterior, o ambiente, o meio, alimentando-se a partir de uma relação dialética entre o interior e o exterior.

Dentre as causas em que as relações entre ideologia e subjetividade ficariam sem solução, tanto no quadro de uma psicologia funcionalista, como no quadro da filosofia, Bakhtin $\backslash$ Voloshinov remetem:

a) à falta de compreensão da natureza específica do signo ideológico, que precisa trabalhar nos limites das fronteiras entre diferentes áreas de conhecimento;

b) às perspectivas idealistas, notadamente kantianas de subjetividade que dão relevância aos estudos da consciência subjetiva individual, reservando à consciência social um papel indefinido e mais metafísico.

Para os autores, por outro lado, não há como tratar do psiquismo como sendo individual e da ideologia somente como sendo social. Daí porque para Bakhtin \Voloshinov as próprias condições através das quais os indivíduos se conscientizam de sua individualidade e de seus direitos são condições históricas e ideológicas, sendo internamente condicionadas por signos sociais que precisam ser entendidos como sendo tanto interiores como exteriores. Eis porque todo signo "inclusive o da individualidade é social.(id.,p.59).

Tratar da lógica da enunciação, sob esta ótica, implica considerar um permanente diálogo entre o exterior e o interior, entre o psíquico e o ideológico, entre a vida interior e a vida exterior, de forma dialética, de tal modo que toda palavra enunciada segue um percurso que está fora do controle do locutor. Esta se subjetiva e produz réplicas, no entanto tais réplicas somente adquirem expressão nas relações conflitantes de valores sociais e ideológicos que se entrecruzam, de tal modo que os espaços de produção e de recepção de sentidos são espaços de movimentos, de contradições permanentes, onde não há lugar para a inércia, para a estabilidade.

Segundo nossa ótica, seria possível fazer corresponder este trabalho de movimento dos sentidos à concepção bakhtiniana de raznorechie, que mobiliza o řech ${ }^{11}$ (discurso), onde o termo remeteria não somente para a idéia de um discurso em outros discursos, mas também para a idéia de co-existência de ideologias conflitantes em um mesmo discurso, configurando a dialética do modo de produção heterogênea dos sentidos nas relações de produção.

Bakhtin $\backslash$ Voloshinov demonstram ter bastante clareza sobre as diferentes lógicas que governam o funcionamento da linguagem como práxis, como enunciação, na medida

\footnotetext{
11 Fazemos referência às reflexões propostas por Brandist (2003), notadamente, em 'Bakhtine, la sociologie du langage et Le Roman', onde o autor caracteriza as formas de hibridação, estratificação da língua (raznojazycie) , e os modos como ela se inscreve em diferentes 'sítios' ideológicos, caracterizando o funcionamento de uma pluralidade de discursos em um mesmo discurso (raznorechie).
} 
em que ao se perguntarem sobre a identidade das leis que governam o sistema interno da língua, concluem que estas são "puramente imanentes e específicas, irredutíveis a leis ideológicas, artísticas ou a quaisquer outras" (id.,p79) que envolvam a inscrição da relação tensa entre formas de expressão social e o trabalho dos sentidos. De maneira dialética, para os autores, todas as formas da língua precisam fazer parte de um sistema estruturado e sujeito a leis lingüísticas específicas. No entanto, tais leis não podem dar conta dos efeitos ideológicos, produzidos pelos sujeitos com a própria língua, das relações de valores distintos e conflitantes que entram em jogo no funcionamento discursivo, por isso precisam ser pensadas a partir de suas contradições.

Para eles, se do ponto de vista sincrônico, como pretendem as tendências objetivistas abstratas ${ }^{12}$, as leis lingüísticas são arbitrárias e privadas de justificativas de ordem ideológica, é porque apagam a história do funcionamento concreto da língua, que passa a ser tomada como "o produto de uma criação coletiva, como uma "instituição meramente normativa"que não cabe questionar.

Se ela for tomada, por outro lado, no processo de observação concreto dos comportamentos linguísticos de uma comunidade determinada é preciso, então, pensar que a língua tem sua história, não pode ser simplesmente encarada como produto, e, portanto, não pode depender de leis estritamente formais.

Eis porque, para Bakhtin $\backslash$ Voloshinov as condições através das quais determinadas comunidades fazem uso da língua acabam por transformar a própria língua, criando novas fórmulas, novas relações entre os significantes e as formas, de tal modo que, para tais comunidades, a lógica da história da língua, em circunstâncias concretas, vem a ser a lógica dos erros ou dos desvios (id.,p.81) que se produzem de formas involuntárias, desapercebidas, mas que passam a fazer parte do próprio processo de transformação da língua, de sua história de estratificações, desafiando até mesmo a rigidez, aparentemente intangível da norma.

Sob o ponto de vista de uma leitura materialista, por conseguinte, o que torna a língua coerente, consistente, a partir de uma ótica objetivista do tipo abstrato, torna-a igualmente inútil enquanto práxis, uma vez que as leis que se aplicam à língua como sistema abstrato, como mero objeto formal, não se "cruzam" com as leis da história das condições que esta trabalha de forma concreta.

Sob uma orientação materialista, portanto, a lógica da língua não pode confinar-se "à repetição de formas identificadas à norma" (id.,p82). Ao contrário, a lógica da língua precisa se concretizar a partir de transformações de estruturas, de estilos, das relações entre motivações ideológicas e a emergência de novos gêneros de discurso, de novos processos de refração de significantes a serem interditados de acordo com os interesses de um dado sistema sócio-político, de dominâncias lexicais que refletem as ordens das práticas .infraestruturais de diferentes grupos. Mas tratar da língua sob tal ótica, para Bakthin $\backslash$ Voloshinov, implica sobretudo a compreensão de que entre a palavra e seu sentido não existem senão vínculos históricos, ainda que para os adeptos do objetivismo abstrato a história possa ser tomada como um domínio irracional capaz de "corromper a pureza lógica do sistema lingüístico.” (id.,p.88).

Eis porque para o observador que enfoca a língua a partir de um olhar "oblíquo" os lapsos de tempo, os eixos de sucessividade temporal que servem de parâmetro à construção de corpora, a fim de dar conta de fatos lingüísticos não passam de uma ficção, já que não

12 Reportamo-nos à leitura crítica feita em 'Marxismo e Filosofia da Linguagem' ao apagamento das questões de subjetividade na linguagem pelas teorias estruturalistas que desconsideram a necessidade de um olhar sobre as relações entre sujeito, língua e suas condições concretas de uso. 
se podem confinar as relações de causalidade a esquemas regulados de temporalidade. Não se trata mais de privilegiar o ponto de vista da diacronia, mas de pensar a relação entre língua e história como uma relação permeada por relações não simétricas, não lineares.

É preciso, portanto, considerar também que Bakhtin\Voloshinov não tratam, em 'Marxismo e Filosofia da Linguagem' das relações entre o funcionamento da língua e a história à semelhança dos lingüistas europeus, embora tenham passado por reflexões sobre as obras de diferentes autores, envolvendo questões tais como as noções objetivistas saussurianas presentes no 'Curso de Linguística Geral'(1991), as reflexões comparatistas humboldtianas ( 1769-1859), as relações simbólicas de Ernst Cassirer (2001), as questões dialógicas presentes na obra de Karl Buhler ,( 1990), nem tampouco conferem prestígio aos estudos filológicos. Pelo contrário, assumem uma posição avessa à influência dos métodos filológicos e, sobretudo, em relação à condição hegemônica que a filologia assume para o desenvolvimento dos estudos lingüísticos no contexto do oeste europeu. Para os autores, a dominância de tendências filológicas nos estudos lingüísticos resultaria em uma compreensão também alienante da própria história.

A fim de tornar mais concreta a questão, comparam as formas de tratamento concedidas ao funcionamento dos enunciados, à enunciação, as quais são dotadas de abstração, incapazes de refletir sobre o funcionamento da língua em termos da experiência, do real. Para Bakhtin\} Voloshinov, ao valorizar a escrita, a norma, em detrimento da fala, das condições concretas de uso da língua, os filólogos somente poderiam entender o funcionamento dos enunciados, a enunciação como sendo monológica, fechada, sem reações ativas à palavra do outro, sem contradições, sem a possiblidade de inscrição em diferentes espaços ideológicos capazes de significá-la. Para os autores, toda e cada enunciação, "mesmo na forma imobilizada da escrita, é uma resposta a alguma coisa e é construída como tal" (id., p.99) Portanto, precisa ser orientada "para uma leitura no contexto da vida científica ou da realidade literária do momento dentro do processo ideológico do qual ela é parte integrante" (id.,p.99

O filólogo-linguista, para eles, ao contrário do que se poderia esperar, no âmbito de uma concepção materialista de linguagem, desvincula os estudos das condições concretas de uso da língua de suas investigações, e portanto, não pode fazer intervir sobre estas compreensões ideológicas ativas, somente pode valer-se de "compreensões passivas" incapazes de comportar reflexões sobre as funções responsiva e ideológica da linguagem. Resta-lhe, assim, a alternativa de realizar estudos comparativos entre estruturas, enunciados, como se tais estruturas pudessem permanecer imunes à transformações da ordem exterior que afeta todas as línguas, ficando a dimensão histórica reduzida a estudos em torno de mudanças do comportamento normativo da língua na ordem do tempo. Deste modo, independentemente, do mito que possa converter o filólogo em "adivinho que tenta decifrar o mistério das letras" e torná-lo acessível à "massa", assim como o mito de que o sacerdote é capaz de desvelar os mistérios da palavra sagrada aos profanos, a filologia, para Bakhtin Voloshinov, deveria cumprir outro papel no estudo das relações entre a linguagem e suas formas de transformação ao longo da história, de modo totalmente distinto dos estudos desenvolvidos por correntes de estudos eurocêntricos dominantes.

\section{Buscando um contraponto}

Embora as condições em que 'Ensaio de Semântica' e 'Marxismo e Filosofia da Linguagem' foram produzidos tenham sido diferentes, na medida em que a autoridade intelectual de Bréal não fora contestada à época, ao contrário das questões filosófico-lin- 
guísticas propostas em 'Marxismo e Filosofia da Linguagem', foi através de um percurso em torno de reflexões que vieram a deslocar princípios lingüísticos, filosóficos e filológicos já sedimentados nos contextos do "Leste e do "Oeste" que pudemos constatar a existência de preocupações comuns entre estes autores em relação:

a) a não separação entre questões de objetividade e subjetividade;

b) às tentativas de caracterizar a lógica de funcionamento da linguagem humana de modo distinto dos princípios positivistas dominantes no final do sec. xix e início do sec. $\mathrm{xx}$;

c) a ênfase dada, pelos autores, à importância de conhecer os processos de transformação histórica de uma língua de modo avesso aos estudos diacrônicos, colocando em primeira perspectiva o trabalho de intervenção da massa falante, do povo, sobre o curso da língua, de forma não sistemática, não-linear, mas espontânea, estando este vinculado a relações de causalidade;

d) aos modos de deslocamento entre os significantes e significados a partir da observação das práticas dominantes entre as massas e das ideologias inscritas em diferentes esferas da criatividade ideológica humana.

Cabe por outro lado, também caracterizar algumas formas de compreensão de tais questões em suas especificidades pelos autores.

Aqui, com base no exposto, a partir dos atributos que definem o papel do lingüista-filólogo, apresentado por Bakhtin/Volochinov, queremos voltar às nossa considerações iniciais acerca dos possíveis entrelaçamentos entre pressupostos que compõem 'Ensaio de Semântica' e pressupostos que constituem 'O Que é a Linguagem' ('Chto Takoe Yazik') e Marxismo e Filosofia da Linguagem'.

Parece-nos estar fora de dúvida o fato de que a questão da subjetividade na obra de Michel Bréal possa estar além de uma leitura crítica acerca da condição de subjetividade designada como 'subjetivismo idealista' em 'Marxismo e Filosofia da Linguagem', na medida em que o vetor que possibilita o entendimento de todo e qualquer processo de transformação de uma língua, sob a ótica de Michel Bréal é o povo, e nisso seus pressupostos acerca das relações entre linguagem e subjetividade adquirem um contorno especial, no contexto do sec. xix, para além das teorias lingüísticas e filológicas dominantes à época.

É importante considerar o fato de que Bréal consegue tornar explícita, em sua obra, a soberania de uma lógica da subjetividade, de caráter orgânico, em detrimento de uma lógica da subjetividade de caráter abstrato e formal. E tais questões viriam, portanto, a torná-lo mais próximo das bases do pensamento 'não-positivista' perseguido por Volochinov/Bakhtin, embora Bréal não tenha sido investigado por Volochinov/Bakhtin, e sim por Antonio Gramsci nas primeiras décadas do sec xx.

Ao contestar o papel da lógica formal como parâmetro para o tratamento da linguagem e dos sentidos, Michel Bréal observa que "todas as formas, no momento em que são usadas, tem direito a existir (id, p.179),dando destaque, sobretudo, ao fato de que" a verdadeira vida da linguagem se concentra nos dialetos", de tal forma que as leis da linguagem vem a coincidir "com o modo como a multidão veste o pensamento" com as suas roupas. (id) E sob este prisma aproxima-se da visão de Bakhtin \Voloshinov sobre a condição essencial de hibridez de toda língua tomada em suas modalidades de dialetização (raznoiaziche).

Essa aproximação, entretanto, encontra seus limites, pois na mesma medida em que Bréal identifica as condições de "mobilidade" da língua às condições de uso que o povo faz dela em situações empíricas, valorizando a massa falante, trata do povo como uma massa indistinta sem relacioná-lo, de modo direto, com questões ideológicas de classe. E 
sob este aspecto afasta-se da visão de Bakhtin \Voloshinov. Daí porque inscrevermos sua ótica sobre a linguagem em um âmbito mais humanista.

Torna, assim, fundamental colocar em destaque, na obra de Bakhtin $\backslash$ Voloshinov, as questões que remetem às relações entre a criatividade ideológica e os gêneros discursivos. Para eles, os diferentes gêneros de discurso, porquanto gêneros de vida e de criatividade ideológica, derivam tanto da infra estrutura como das superestruturas, de tal modo que a caracterização de um gênero discursivo está sempre permeada pelos interesses de classe, dependendo de injunções de ordem sócio-política. E segundo nossa ótica, esta visão torna-se lacunar na visão humanista de linguagem e de subjetividade proposta por Michel Bréal.

Outra questão que merece destaque, consiste no modo como Bréal entrelaça o sujeito e o enunciador: ao buscar tratar de questões de subjetividade como sendo constitutivas da objetividade da língua. Trata-as de modo a colocar o enunciador como protagonista e, ao mesmo tempo espectador de sua fala, mas sem buscar relações dialéticas entre a palavra do "ego" e a palavra do outro, o que vem a caracterizar sua visão específica de subjetividade. Bakhtin/Volochinov, por outro lado, ao tratarem da subjetividade como não sendo nem individual nem universal, tendo a enunciação uma função ativa de resposta à palavra do outro, á ideologia do outro, sendo esta constitutivamente marcada por um cruzamento de vozes em 'diálogo permanente, acabam por refletir sobre diferentes modos de subjetivação da realidade externa, inscritos em ordens que são sociológicas e ao mesmo tempo se inscrevem em pressupostos do materialismo histórico.

Cabe considerar ainda que Bréal, ao tratar do modo como os sentidos operam na linguagem, dá destaque ao trabalho de leis lógicas, que, oriundas da observação sobre os modos como a língua se transforma em suas condições concretas de uso pela massa, permitem-nos estabelecer relações entre a língua, suas condições de uso e a história.

Bakhtin $\backslash$ Voloshinov, por sua vez, tratam do signo ideológico para tratar do sentido. O signo, para os autores, sendo um fenômeno de ordem simbólica e do mundo externo é sempre dotado de uma corporeidade de diferentes ordens que inscreve o social e o ideológico em seu interior. E é justamente esta corporeidade múltipla - da língua e do mundo - que irá determinar suas formas de objetivação. Assim, enquanto em Bréal tratamento dos sentidos pode ser apreendido por meio de um percurso histórico não linear e fragmentado em virtude das condições intervenção das massas no uso da língua, em Bakhtin \Voloshinov a relação entre a língua - objeto neutro- e o signo - símbolo ideológico depende de questões de ordem dialética, ainda que, segundo as questões que focalizamos neste estudo nos demonstrem que estes autores, ao seu modo, em momentos históricos distintos e em contextos geográficos diferentes tenham, igualmente, empreendido esforços para superar a influência dominante das concepções de base positivista nos domínios da Filologia, da Lingüística e da Filosofia da Linguagem.

Por fim, entendemos que as óticas destes autores seriam representativas de visões incomuns, entre os lingüistas e filólogos durante o final do século xix e início do século $\mathrm{xx}$, na medida em que viriam não somente questionar mas também destituir de posições dominantes muitos princípios tidos como inquestionáveis entre os linguistas europeus durante o final do século xix e as primeiras três décadas do sec. xx, tais como:

a) o princípio de que a Linguística seria uma "ciência natural;

b) a visão de que o papel da filologia consistiria em investigar as transformações das estruturas das línguas, de forma comparada, independentemente de suas relações com as condições empíricas de uso das mesmas pela massa falante; 
c) a condição de que o tratamento da lógica da linguagem humana precisa estar sujeito aos paradigmas da lógica simbólica aplicada às línguas naturais; d) o princípio de que a produção do conhecimento sobre as leis que governam as condições de transformação dos significados das palavras pode se dar sem o acesso a estudos em torno das formas de subjetivação dos sujeitos nalpela linguagem;

e) o postulado de que a história poderia ser reduzida à mera condição de diacronia.

Eis porque, segundo nossa ótica, tornou-se fundamental aproximar uma leitura humanista de uma leitura marxista de linguagem, considerando que é pelas especificidades de cada uma que conseguimos escapar dos laços hegemônicos que ainda amarram a Lingüística à influência de saberes de ordem positivista.

\section{Referências}

BAKHTIN, Mikhail, VOLOSHINOV, V. Marxismo e filosofia da linguagem. Problemas fundamentais do método sociológico na ciência da linguagem. São Paulo, Ed. Hucitec, 1986. Trad. Michel Lahud e Yara Frateschi et al.

BRANDIST, Craig. Bakhtine,: la sociologue du langage et le roman. In:Cahiers de l'ILSL, no 14, Lausanne, Université de Lausanne, 2003, p.59-84.

BRÉAL, Michel. Ensaio de semântica. Ciência das significações.Camoinas, Ed. Pontes, 1992. Trad. Eduardo Guimarães et al.

BUHLER, Karl. Theory of language. The representational function of language. Foundations of Semiotics, vol25, New York, John Benjamins Ed., 1990

CASSIRER, Ernst. A filosofia das formas simbólicas. São Paulo: Ed. Martins Fontes,2001.

Trad. Marion Fleischer

DARMESTETER, Arsène. La vie des mots dans leur significations. Paris: Ed. Champ Libre, 1979.

GRAMSCI, Antonio. Concepção dialética da história. Rio de Janeiro: Ed. Civilização Brasileira, 1989. Trad. Carlos Nelson Coutinho

HERMANN, Paul. Princípios fundamentais da história da língua. Lisboa: Fundação Calouste Gulbenkian, 1983.

MARX, Karl, ENGELS, Friedrich. A ideologia alemã.São Paulo: Ed. Martins Fontes, 2007. Trad. Luis Claudio de Castro e Costa

MULLER, Max. Contributions to the science of mithology. London, Longmans, Geen \& Co, 2008.

SAUSSURE, Ferdinand de. Curso de lingüística geral.São Paulo: Ed. Cultrix, 1991. Trad.Antônio Chelini et al.

SCHLEICHER,A. The Darwinian theory and the science of language. In: Amsterdam Classics in linguistics. New York, John Benjamins Ed., 1983.

VOLOSHINOV, Valentin. Q'uest ce que la langue et le langage? (Chto Takoe Yazik).In: Marxisme et philosophie du langage. Les problèmes fundamentaux de Hla méthode sociologique dans la science du langage. Limoges, Ed. Lambert-Lucas, 2010. Trad et organisation Patrick Sériot e Inna Tilkowsky-Ageeva.

VOLOSINOV,V.N. Marxism and the philosophy of language.Cambridge:Massachusetts, 1986 Translated by Ladislav Matejka and I. R. Titunik 